\title{
Topical Tacrolimus for Psoriasis
}

\author{
Toshiyuki Yamamoto*
}

Department of Dermatology, Fukushima Medical University, Fukushima, Japan

\begin{abstract}
Tacrolimus ointment is an agent approved for the treatment of atopic dermatitis; however, tacrolimus has been expected also as one of the promising therapeutic strategies for other T-cell mediated inflammatory skin disorders. Recent progress have demonstrated that topical tacrolimus shows beneficial effects for psoriasis depending on sites. In particular, facial, intertriginous, and genital psoriasis respond to topical tacrolimus dramatically in a short period. Further, topical tacrolimus is tolerable also for child psoriasis. Because topical tacrolimus does not induce either skin atrophy or telangiectasia different from corticosteroids, it is recommended to be a first choice. The most proper way of topical tacrolimus therapy at present is to use this ointment intermittently after the remission was once obtained, paying attention to its adverse effects.
\end{abstract}

\section{INTRODUCTION}

Tacrolimus (FK 506) is a macrolide molecule isolated from the fermentation broth of Streptomyces tsukubaensis, which has an immunosuppressive property. Topical tacrolimus is approved for the treatment of atopic dermatitis of adult and also children. A number of studies have shown that topical tacrolimus is effective for a broad spectrum of inflammatory skin disorders. Apart from corticosteroids, topical tacrolimus does not cause either skin atrophy or telangiectasia even by long-term use, which is the major advantage of this drug. One of the possible explanation is that tacrolimus does not affect endothelial cells, keratinocytes and fibroblasts, and thus does not affect collagen synthesis $[1,2]$ and skin thickness [3]. In this review, I have made a focus on a therapeutic option of topical tacrolimus for psoriasis.

\section{PHARMACOLOGY OF TACROLIMUS}

Tacrolimus is the topical calcineurin inhibitor. Calcineurin is a calcium-binding cytoplasmic protein that is involved in T-cell activation and proliferation. Tacrolimus binds to FK506, and the complex further binds to calcineurin and prevents the dephosphorylation of the nuclear factor of activated T-cells (NFAT), which lead to the blocking of cascade of cytokine gene transcription, such as interleukin-2 (IL-2), IL-4, interferon- $\gamma$ (IFN- $\gamma$ ), and tumor necrosis factor- $\alpha$ (TNF- $\alpha$ ) [4]. Other immunomodulatory effects of tacrolimus include the inhibition of mast cell adhesion, the inhibition of the release of the mediators from mast cells and basophils, and the downregulation of the expression of IL-8 receptor [5-7]. Tacrolimus ointment has an inhibitory effect on the function of Langerhans cells [8], and inhibited the in vitro $\mathrm{T}$-cell stimulatory effect of antigen presenting dendritic cells [9]. Upon keratinocytes, FK506 upregulated transforming growth factor- $\beta$ (TGF- $\beta$ ) produc-

\footnotetext{
*Address correspondence to this author at the Department of Dermatology, Fukushima Medical University, Hikarigaoka 1, Fukushima 960-1295 (Japan); Tel: +81 24547 1307; Fax: +81 24548 5412;

E-mail: toyamade@fmu.ac.jp
}

tion, downregulated inducible nitric oxide synthase (iNOS) production [10], and inhibited TNF- $\alpha$ secretion via regulation of NF-kB [11]. Other studies showed that topical tacroimus therapy reduced the expresson of adhesion molecules [12] and some chemokines which recruits eosinophils [13] in the lesional skin of atopic dermatitis.

The possible mechanism of anti-pruritic effect of tacrolimus may be attributed to the reduction of the levels of nerve growth factor, substance $\mathrm{P}$, and neurotrophin-3 in the lesional skin $[14,15]$.

Additionally, tacrolimus reduces the colonization of Staphylococcus aureus in the skin of atopic dermatitis [16, 17], which is considered to result from the improvement of skin inflammation and consequently the repair of barrier function.

\section{TOPICAL TACROLIMUS THERAPY FOR PSORIASIS}

Psoriasis is a chronic inflammatory skin disorder, which is clinically characterized by circumscribed red plaques covered with white scales on the surface. Histological features show proliferation of epidermis with parakeratosis, dilation of superficial blood vessels, polymorphonuclear leukocyte infiltration in the stratum corneum, and perivascular infiltration of mononuclear cells in the upper dermis. A growing body of evidence has shown that immunologic mechanisms are involved, and activated T-cells play a crucial role, via an array of proinflammatory cytokines, in the pathogenesis of psoriasis. In psoriasis, activated T-cells predominantly release Th1 cytokines such as IL-2, IFN- $\alpha$ and TNF- $\alpha$. In particular, TNF- $\alpha$ stimulates keratinocyte proliferation, T-cell and macrophage cytokine production, and expression of adhesion molecules on vascular endothelial cells. In the involved skin of psoriasis, TNF, TNF-receptor1, -receptor2 are upregulated in dermal blood vessels [18]. Biological therapies targeting TNF have been achieved beneficial effects and improved quality of life of patients. TNF is a key regulator of the inflammatory response, and there are a number of TNF-mediated inflammatory diseases [19]. The signaling pathway of TNF might trigger psoriasis. On the other hand, recent advances indicate that psoriasis is a Th17-mediated inflammatory disease [20]. Th17 cells 

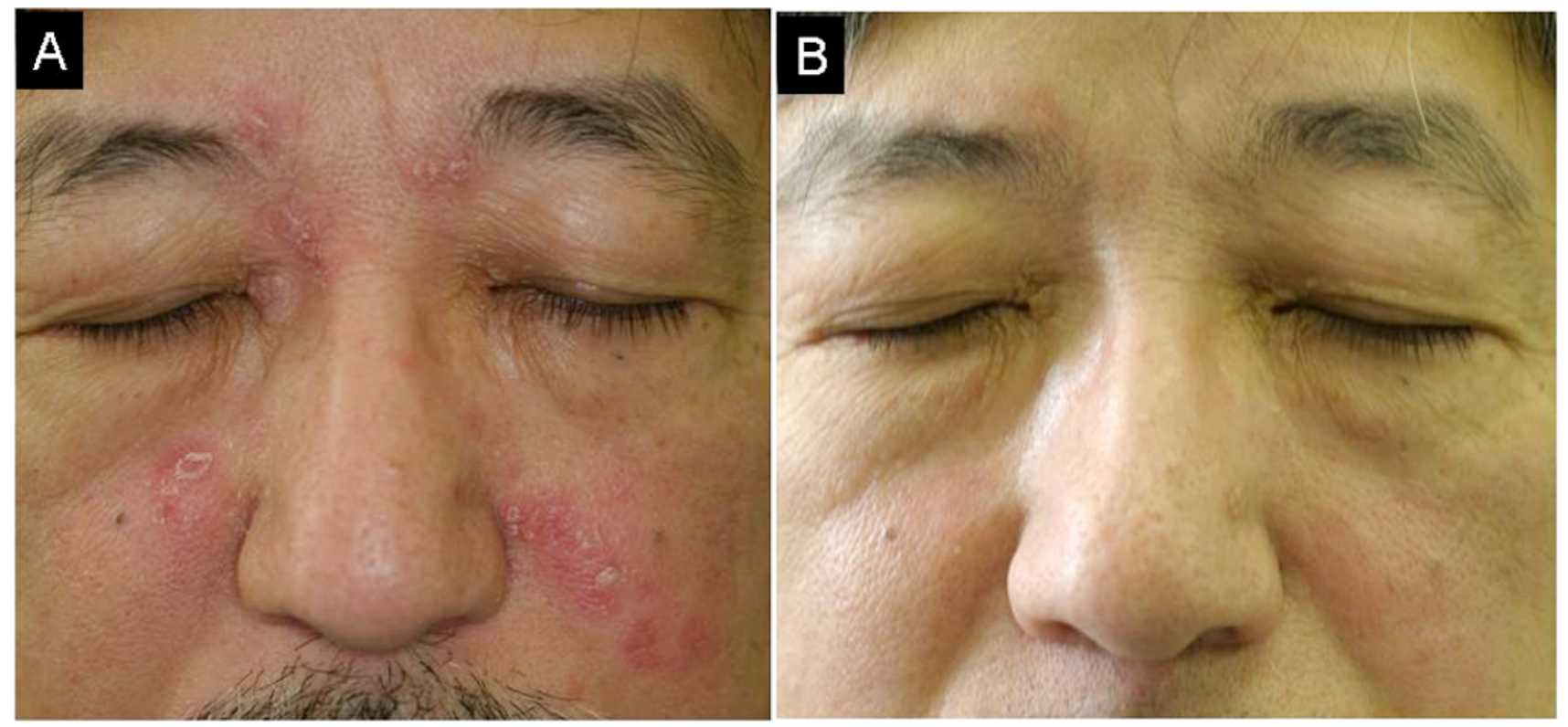

Fig. (1). Beneficial effect of topical tacrolimus for facial psoriasis. (A) Pre-treatment; (B) after 2 weeks.

produce IL-17, which promotes neutrophil migration [21]. Also, Th17 cells secret IL-6, IL-21, IL-22, TNF- $\alpha$, and IFN$\gamma$. IL-23 promotes the expression of IL-17, and upregulates IL-22. IL-22 has effects on keratinocyte proliferation and differentiation. Thus, the IL-23/IL-17 inflammatory pathway is central to the pathogenesis of psoriasis [22].

The efficacy of topical tacrolimus ointment for chronic psoriasis plaques is controversial [23-25], because the absorption of this drug is interfered by the thick scales of psoriasis. Previous studies showed that no significant difference was found in the effect between topical tacrolimus ointment and placebo, although $0.3 \%$ topical tacrolimus was applied only once daily in a pilot study [23]. By contrast, with the improvement of the disadvantage of absorption of this drug by occlusion method every 2-3 days, application of $0.3 \%$ tacrolimus ointment resulted in a significant reduction in erythema, infiltration, superficial blood flow, and epidermal thickness, compared with the control vehicle [24]. Another method of increasing the penetration of tacrolimus is to use combined with $6 \%$ salicylic acid gel, which is reported to be effective for plaque-type psoriasis [26]. Tacrolimus moderately effected on epidermal proliferation, and reduced several T-cell subsets infiltrated in the lesional psoriatic skin, but these effects were significantly induced by calcipotriol [27].

On the other hand, we for the first time reported that topical tacrolimus shows dramatical effect for facial psoriatic lesions [28]. Since then, several reports demonstrated that topical tacrolimus is highly effective for facial and intertriginous psoriasis [29-32]. In an open-label trial, $0.1 \%$ tacrolimus ointment was applied twice daily for 8 weeks for the facial or intertriginous areas in 21 patients with psoriasis [29]. A total of $81 \%$ (17 of 21 patients) showed complete clearance at day 57. Our open-labeled, uncontrolled trial also showed similar effects, and an improvement in erythema, infiltration and desquamation of the facial psoriasis was obtained by 4 -weeks' $0.1 \%$ tacrolimus ointment without occlusion [30]. A complete clearance was noted in 10 patients $(47.6 \%)$. In a randomized, double-blinded, controlled, multicenter study, 167 patients were treated with tacrolimus for 8 weeks [31]. As early as day 8, more patients had experienced clearance or excellent improvement, and at the end of the 8 -week treatment period, $65.2 \%$ of the tacrolimus ointment group were clear or almost clear, with a significant predominance compared with control group. On the other hand, topical tacrolimus is effective for not only mild but also severe facial plaque psoriasis, although in a single case report [33]. Additionally, tacrolimus is tolerably effective for intertriginous and genital psoriasis [29, 34-36]. Tacrolimus was significantly more effective for facial and genitofemoral areas of psoriasis, compared with calcitriol ointment [37]. Taken together, topical tacrolimus is successfully used for facial and intertriginous psoriasis [38], even in pediatric patients [39, 40]. Facial psoriasis lesions are usually not covered by thick scales, and thus the penetration is not blocked, which may in part explain the efficacy of topical tacrolimus. A representative photographs before and after topical tacrolimus therapy are shown in Fig. (1). Tacrolimus is tolerably effective even for the sites close to the eye (Fig. 2). In the majority of cases, facial psoriasis improved as early as 1 week; however, relapse is frequently seen. Therefore, it is recommended to use tacrolimus ointment intermittently thereafter.

Oral manifestations are rare in psoriasis [41]. A geographic tongue with marked fissuring is frequently associated with pustular psoriasis; however, the incidence of oral manifestations is considered to be less than $2 \%$ of patients with psoriasis vulgaris. In most of the reported cases, the clinical course of the oral lesions parallel with that of cutaneous lesions, and oral psoriasis exclusively presenting oral involvement is extremely rare $[42,43]$. Oral psoriasis is clinically classified into two groups; well-defined, silvery or grayish white lesions and a diffuse erythema of the mucosa. Lip lesions respond well to topical tacrolimus ointment [44]. 

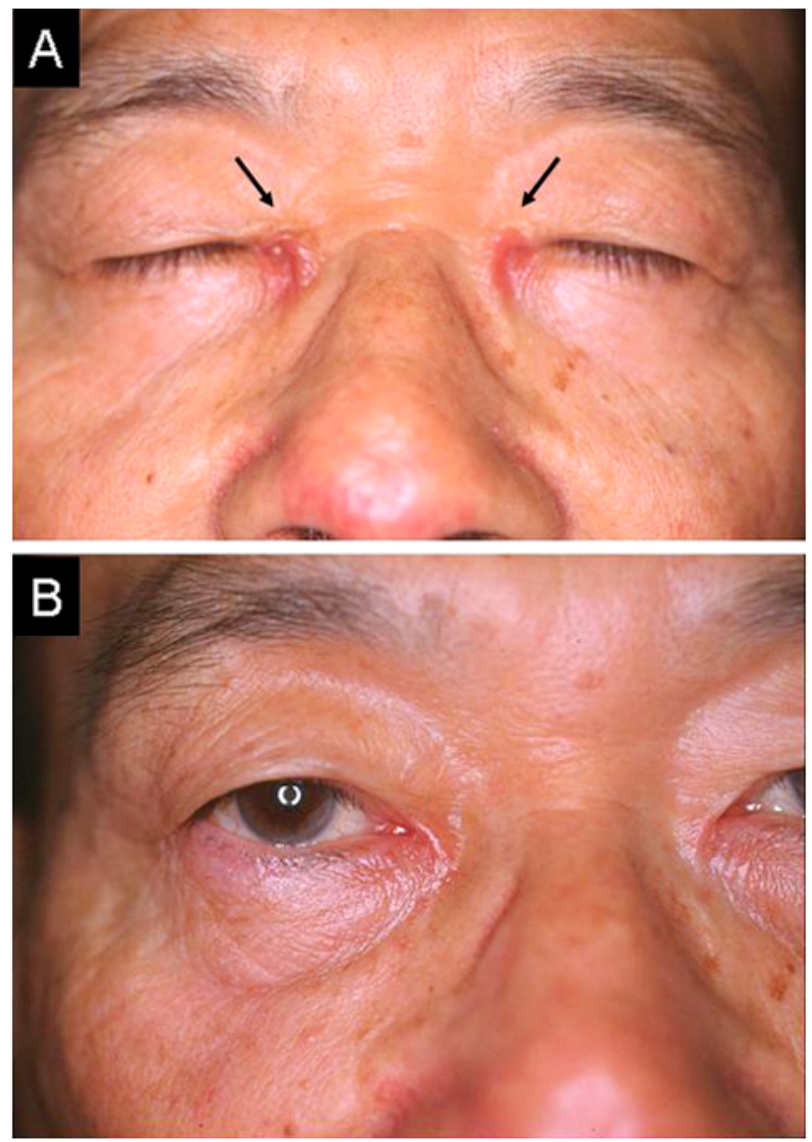

Fig. (2). Topical tacrolimus is tolerably effective even for sites close to the eye (arrow). (A) Pre-treatment; (B) after 1 week.

Additionally, topical tacrolimus is shown to be effective for pustular psoriasis, with [45] or without [46] oral immunosuppressive therapy.

\section{THERAPEUTIC OPTIONS FOR OTHER INFLAM- MATORY SKIN DISORDERS}

Topical application of tacrolimus has been shown to be effective in the treatment of several inflammatory skin disorders other than atopic dermatitis and psoriasis [47, 48]. Tacrolimus inhibits calcineurin, which consequently suppresses activation and differentiation of T-cells as well as other proinflammatory cytokines. Thus, a number of therapeutic usefulness of topical tacrolimus in particular for Tcell mediated skin diseases, such as eczema, seborrheic dermatitis, pyoderma gangrenosum, lichen planus, lichen sclerosus, vitiligo, alopecia areata, and so on [49]. Additionally, topical tacrolimus is occasionally effective for other disorders which are not always $\mathrm{T}$ cells play a central role in the pathogenesis, suggesting that tacrolimus may possess various pharmacological mode of action.

From the viewpoint of site of application, tacrolimus is dramatically effective for membranous lesions, such as orogenital areas. It is well-known, and there are a number of reports that topical tacrolimus is effective for oral $[50,51]$ and vulvovaginal $[52,53]$ lichen planus. Lichen sclerosus on the mucous sites (lip, vulvar) are also reported to be suc-

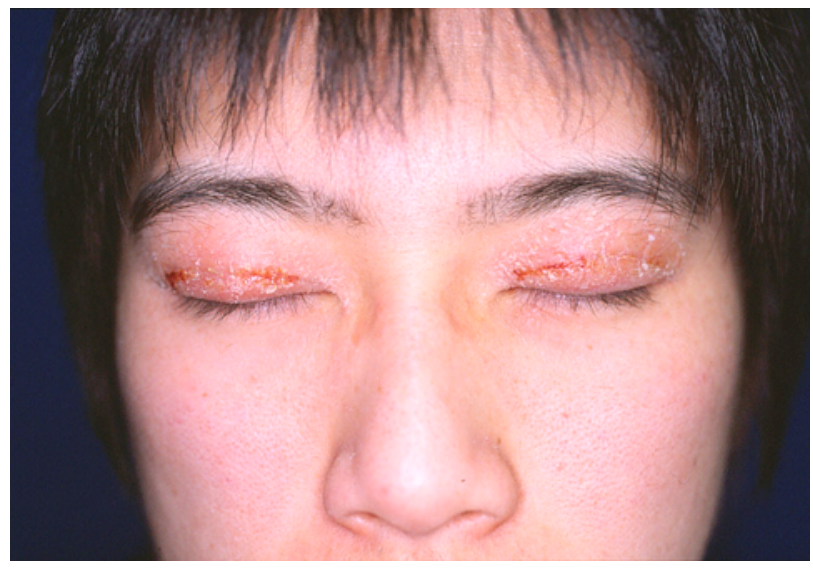

Fig. (3). Prominent scaly erythema on the upper lids induced by $0.1 \%$ tacrolimus eye drops.

cessfully treated with $0.3 \%$ tacrolimus ointment [54-57]. Of interest, comedos in the genital areas complicated by lichen sclerosus were also improved [56]. Additionally, another report have shown that topical tacrolimus is effective for perianal ulcerating Crohn's disease [58]. These results suggest the site-specific effectiveness for topical tacroimus therapy.

\section{ADVERSE EFFECTS OF TOPICAL TACROLIMUS THERAPY}

The most common adverse effects of topical tacrolimus therapy are sensation of the skin burning, pruritus, flu-like symptoms, skin erythema, and headache. In most of the cases, tacrolimus is tolerable for facial use. Herpes simplex infection is occasionally seen on the face during topical tacrolimus therapy. Other less common symptoms include eczema herpeticum, molluscum contagiosum, and warts. As described before, topical tacrolimus is effective especially for facial psoriasis; however, deep fungal infection is rarely reported [59]. Tacrolimus rarely induces allergic contact dermatitis [60]. Patch test shows delayed reaction. Fig. (3) shows a peri-ocular scaly erythema during preclinical trial with FK506 eye drops $(0.1 \%)$ for severe catarrhal conjunctivitis, which was suspicious of allergic contact dermatitis. Also, topical tacrolimus is effective for rosacea, whereas a rosacea-like granulomatous eruption appeared during tacrolimus use [61, 62], thus attention should be paid. Although there may be a risk of lymphoma related to topical tacrolimus in animal studies, there are so far no reports of malignancy occurrence during topical tacrolimus use in healthy individuals.

\section{CONCLUSION}

Topical tacrolimus is a promising tool which is expected as a useful and safe therapeutic option for psoriasis, especially on the facial, intertriginous and genital areas. Because patients worry about the outlook of facial psoriasis, tacrolimus may help to release the stress and improve their quality of life. Further studies which prove the efficacy and safety of tacrolimus ointment for psoriasis will be necessary.

\section{REFERENCES}

[1] Reitamo S, Rissanen J, Remitz A, et al. Tacrolimus ointment does not affect collagen synthesis: results of a single-center randomized trial. J Invest Dermatol 1998; 111: 396-8 
[2] Kyllonen H, Remitz Z, Mandelin JM. Effects of 1-year intermittent treatment with topical tacrolimus monotherapy on skin collagen synthesis in patients with atopic dermatitis. Br J Dermatol 2004; 150: 1174-81.

[3] Kikuchi K, Tagami H. Comparison of the effects of daily applications between topical corticosteroid and tacrolimus ointments on normal skin: evaluation with noninvasive methods. Dermatology 2002; 205: 378-82.

[4] Simpson D, Noble S. Tacrolimus ointment: a review of its use in atopic dermatitis and its clinical potential in other inflammatory skin conditions. Drugs 2005; 6: 827-58.

[5] Columbo M, Bochner BS, Marone G. Human mast cells express functional beta 1 integrins that mediate adhesion to extracellular matrix proteins. J Immunol 1995; 154: 6058-64.

[6] Schulz BS, Michel G, Wagner S, et al. Increased expression of epidermal IL-8 receptor in psoriasis: down-regulation by FK-506 in vitro. J Immunol 1993; 151: 4399-406.

[7] Lemster BH, Carroll PB, Rilo HR, Johnson N, Nikaein A, Thomson AW. IL-8/IL-8 receptor expression in psoriasis and the response to systemic tacrolimus (FK506) therapy. Clin Exp Immunol 1995; 99: 148-54.

[8] Panhans-Gross A, Novak N, Kraft S, Bieber T. Human epidermal Langerhans cells are targets for the immunosuppressive macrolide tacrolimus (FK506). J Allergy Clin Immunol 2001; 107: 345-52.

[9] Wollenberg A, Sharma S, von Bubnoff D, Geiger E, Haberstok J, Bieber T. Topical tacrolimus (FK506) leads to profound phenotypic and functional alterations of epidermal antigen-presenting dendritic cells in atopic dermatitis. J Allergy Clin Immunol 2001; 107: 519-25.

[10] Lan CC, Kao YH, Huang SM, Yu HS, Chen GS. FK506 independently upregulates transforming growth factor beta and downregulates inducible nitric oxide synthase in cultured human keratinocytes: possible mechanisms of how tacrolimus ointment interacts with atopic skin. Br J Dermatol 2004; 151: 679-84.

[11] Lan CC, Yu HS, Wu CS, Kuo HY, Chai CY, Chen GS. FK506 inhibits tumor necrosis factor-alpha secretion in human keratinocytes via regulation of nuclear factor-kappaB. Br J Dermatol 2005; 153: 725-32.

[12] Caproni M, Torchia D, Antiga E, Volpi W, Fabbri P. Expression of adhesion molecules in atopic dermatitis is reduced by tacrolimus, but not by hydrocortisone butyrate: a randomized immunohistochemical study. Clin Exp Dermatol 2006; 31: 813-7.

[13] Park CW, Lee BH, Han HJ, Lee CH, Ahn HK. Tacrolimus decreases the expression of eotaxin, CCR3, RANTES and interleukin-5 in atopic dermatitis. Br J Dermatol 2005; 152: 1173-81.

[14] Toyoda M. Antipruritic mechanism of tacrolimus ointment for atopic dermatitis: consideration of dermatoneuronal factors. Clin Dermatol 2003; 57: 45-50.

[15] Kim HO, Lee CH, Ahn HK, Park CW. Effects of tacrolimus ointment on the expression of substance $P$, nerve growth factor, and neurotrophin-3 in atopic dermatitis. Int J Dermatol 2009; 48: 4318.

[16] Remitz A, Kyllonen H, Granlund H, Reitamo S. Tacrolimus ointment reduces staphylococcal colonization of atopic dermatitis lesions. J Allergy Clin Immunol 2001; 107: 196-7.

[17] Pournaras CC, Lubbe J, Saurat J-H. Staphylococcal colonization in atopic dermatitis treatment with topical tacrolimus (FK506). J Invest Dermatol 2001; 116: 480-1.

[18] Kristensen M, Chu CQ, Eedy DJ, Feldmann M, Brennan FM, Breathnach SM. Localization of tumour necrosis factor-alpha $(\mathrm{TNF} \alpha)$ and its receptors in normal and psoriatic skin: epidermal cells express the $55 \mathrm{kDa}$ but not the $75 \mathrm{kDa}$ TNF receptor. Clin Exp Immunol 1993; 94: 354-62.

[19] Bradley JR. TNF-mediated inflammatory disease. J Pathol 2008; 214: $149-60$.

[20] Nestle FO, Kaplan DH, Baker J. Psoriasis. N Engl J Med 2009; 361: 496-509.

[21] Laan M, Cui ZH, Hoshino $\mathrm{H}$, et al. Neutrophil recruitment by human IL-17 via C-X-C chemokine release in the airways. J Immunol 1999; 162: 2347-52.

[22] Cesare AD, Meglio PD, Nestle FO. The IL-23/Th17 axis in the immunopathogenesis of psoriasis. J Invest Dermatol 2009; 129: $1339-50$.
[23] Zonneveld IM, Rubins A, Jablonska S, et al. Topical tacrolimus is not effective in chronic plaque psoriasis. A pilot study. Arch Drmatol 1998; 134: 1101-2

[24] Remitz A, Reitamo S, Erkko P, Granlund H, Lauerma AI. Tacrolimus ointment improves psoriasis in a microplaque assay. Br J Dermatol 1999; 141: 103-7.

[25] Ortonne JP, van de Kerkhof PC, Prinz JC, et al. European tacrolimus psoriasis study group. $0.3 \%$ tacrolimus gel and $0.5 \%$ tacrolimus cream show efficacy in mild to moderate plaque psoriasis: results of a randomized, open-label, observer-blinded study. Acta Derm Venereol 2006; 86: 29-33.

[26] Carroll CL, Clarke J, Camacho F, Balkrishnan R, Feldman SR. Topical tacrolimus ointment combined with $6 \%$ salicylic acid gel for plaque psoriasis treatment. Arch Dermatol 2005; 141: 43-6.

[27] Vissers WH, van Vlijmen I, van Erp PE, de Jong EM, van de Kerkhof PC. Topical treatment of mild to moderate plaque psoriasis with $0.3 \%$ tacrolimus gel and $0.5 \%$ tacrolimus cream: the effect on SUM score, epidermal proliferation, keratinization, T-cell subsets and HLA-DR expression. Br J Dermatol 2008; 158: 705-12.

[28] Yamamoto T, Nishioka K. Topical tacrolimus is effective for facial psoriasis. Acta Derm Venereol 2000; 80: 451.

[29] Freeman AK, Linowski GJ, Brady C, et al. Tacrolimus ointment for the treatment of psoriasis on the face and intertriginous areas. J Am Acad Dermatol 2003; 48: 564-8.

[30] Yamamoto T, Nishioka K. Topical tacrolimus: an effective therapy for facial psoriasis. Eur J Dermatol 2003; 13: 471-3.

[31] Lebwohl M, Freeman AK, Chapman MS, Feldman SR, Hartle JE, Henning A. Tacrolimus ointment study group. Tacrolimus ointment is effective for facial and intertriginous psoriasis. J Am Acad Dermatol 2004; 51: 723-30.

[32] Clayton TH, Harrison PV, Nicholls R, Delap M. Topical tacrolimus for facial psoriasis. Br J Dermatol 2003; 149: 419-20.

[33] Kroft EB, Erceg A, Maimets K, Vissers W, van der Valk PG, van de Kerkhof PC. Tacrolimus ointment for the treatment of severe facial plaque psoriasis. J Eur Acad Dermatol Venereol 2005; 19: 249-51.

[34] Martin Ezquerra G, Sanchez Regana M, Herrera Acosta E, Umbert Millet P. Topical tacrolimus for the treatment of psoriasis on the face, genitalia, intertriginous area and corporal plaques. J Drugs Dermatol 2006; 5: 334-6.

[35] Bissonnette R, Nigen S, Bolduc C. Efficacy and tolerability of topical tacrolimus ointment for the treatment of male genital psoriasis. J Cu$\tan$ Med Surg 2008; 12: 230-4.

[36] Ralis E, Nasiopoulou A, Kouskoukis C, et al. Successful treatment of genital and facial psoriasis with tacrolimus ointment $0.1 \%$. Drugs Exp Clin Res 2005; 31: 141-5.

[37] Liao YH, Chiu HC, Tseng YS, Tsai TF. Comparison of cutaneous tolerance and efficacy of calcitriol 3 micro $\mathrm{g}(-1)$ ointment and tacrolimus $0.3 \mathrm{mg} \mathrm{g(-1)} \mathrm{ointment} \mathrm{in} \mathrm{chronic} \mathrm{plaque} \mathrm{psoriasis} \mathrm{involving}$ facial or genitofemoral areas: a double-blind, randomized controlled trial. Br J Dermatol 2007; 157: 1005-12.

[38] Kalb RE, Bagel J, Korman NJ, et al. National Psoriasis Foundation. Treatment of intertriginous psoriasis: from the Medical Board of the National Psoriasis Foundation. J Am Acad Dermatol 2009; 60: 120-4.

[39] Brune A, Miller DW, Lin P, Cotrim-Russi D, Paller AS. Tacrolimus ointment is effective for psoriasis on the face and intertriginous areas in pediatric patients. Pediatr Dermatol 2007; 24: 76-80.

[40] Steele JA, Choi C, Kwong PC. Topical tacrolimus in the treatment of inverse psoriasis in children. J Am Acad Dermatol 2005; 53: 713-6.

[41] Yamamoto T, Nishioka K. Oral psoriasis in a patient with hepatitis C virus infection. Eur J Dermatol 2002; 12: 75-6.

[42] Sklavounou A, Laskaris G. Oral psoriasis: report of a case and review of the literature. Dermatologica 1990; 180: 157-9.

[43] Rozell B, Grever A-C, Marcusson JA. Oral psoriasis: report on a case without epidermal involvement. Acta Derm Venereol 1997; 77: 399400.

[44] Yamamoto T, Nishioka K. Sucessful treatment with topical tacrolimus for oral psoriasis. J Eur Acad Dermatol Venereol 2006; 20 : $1137-8$.

[45] Rodriguez GF, Fagundo GE, Cabrera-Paz R, et al. Generalized pustular psoriasis successfully treated with topical tacrolimus. Br J Dermatol 2005; 152: 587-8.

[46] Nagao K, Ishiko A, Yokoyama T, Tanikawa A, Amagai M. A case of generalized pustular psoriasis treated with topical tacrolimus. Arch Dermatol 2003; 139: 1219.

[47] Wollina U. The role of topical calcineurin inhibitors for skin diseases other than atopic dermatitis. Am J Clin Dermatol 2007; 8: 157-73. 
[48] Luger T, Paul C. Potential new indications of topical calcineurin inhibitors. Dermatology 2007; 215: 45-54.

[49] Evans AV. The expanding role of topical tacrolimus in dermatology. Clin Exp Dermatol 2005; 30: 111-5.

[50] Byrd JA, Davis MD, Bruce AJ, Drage LA, Rogers RS $3^{\text {rd }}$. Response of oral lichen planus to topical tacrolimus in 37 patients. Arch Dermatol 2004; 140: 1508-12.

[51] Hodgson TA, Sahni N, Kaliakatsou F, Buchanan JA, Porter SR. Long-term efficacy and safety of topical tacrolimus in the management of ulcerative/erosive oral lichen planus. Eur J Dermatol 2003; 13: 466-70.

[52] Kirtschig G, van der Meulen AJ, Ion Lipan JW, Stoof TJ. Successful treatment of erosive vulvovaginal lichen planus with topical tacrolimus. Br J Dermatol 2002; 147: 625-6.

[53] Lotery HE, Galask RP. Erosive lichen planus of the vulva and vagina. Obstet Gynecol 2003; 101: 1121-5.

[54] Assmann T, Becker-Wegerich P, Grewe M, Megahed M, Ruzicka T. Tacrolimus ointment for the treatment of vulvar lichen sclerosus. J Am Acad Dermatol 2003; 48: 935-7.

[55] Kunstfeld R, Kirnbauer R, Stingl G, Karlhofer FM. Successful treatment of vulvar lichen sclerosus with topical tacrolimus. Arch Dermatol 2003; 139: 850-2.
[56] Matsumoto Y, Yamamoto T, Isobe T, Kusunoki T, Tsuboi R. Successful treatment of vulvar lichen sclerosus in a child with lowconcentration topical tacrolimus ointment. J Dermatol 2007; 34: 1146.

[57] Wakamatsu J, Yamamoto T, Uchida H, Tsuboi R. Successful treatment of lichen sclerosus of the lip. J Eur Acad Dermatol Venereol 2008; 22 : 760-2.

[58] Hart A, Plamondon S, Kamm MA. Topical tacrolimus in the treatment of perianal Crohn's disease: Exploratory randomized controlled trial. Inflamm Bowel Dis 2007; 13: 245-53.

[59] Yamamoto T, Nishioka K. Deep dermatophytosis during topical tacrolimus therapy for psoriasis. Acta Derm Venereol 2003; 83: 2912 .

[60] Shaw DW, Eichenfield LF, Shainhouse T, Maibach HI. Allergic contact dermatitis from tacrolimus. J Am Acad Dermatol 2004; 50: 962-5.

[61] Bernard LA, Cunningham BB, Al-Suwaidan S, Friedlander SF, Eichenfield LF. A rosacea-like granulomatous eruption in a patient using tacrolimus ointment for atopic dermatitis. Arch Dermatol 2003; 139: 229-31.

[62] Antille C, Saurat JH, Lübbe J. Induction of rosaceaform dermatitis during treatment of facial inflammatory dermatoses with tacrolimus ointment. Arch Dermatol 2004; 140: 457-60.

(C) Toshiyuki Yamamoto; Licensee Bentham Open.

This is an open access article licensed under the terms of the Creative Commons Attribution Non-Commercial License (http://creativecommons.org/licenses/by-nc/3.0/) which permits unrestricted, non-commercial use, distribution and reproduction in any medium, provided the work is properly cited. 